\title{
Disulfiram Attenuates Drug-Primed Reinstatement of Cocaine Seeking via Inhibition of Dopamine $\beta$-Hydroxylase
}

\author{
Jason P Schroeder ${ }^{1,6}$, Debra A Cooper ${ }^{1,6}$, Jesse R Schank', Megan A Lyle', Meriem Gaval-Cruz', \\ Yvonne E Ogbonmwan', Nikita Pozdeyev', Kimberly G Freeman ${ }^{3}$, P Michael luvone ${ }^{2,4}$, Gaylen L Edwards ${ }^{3}$, \\ Philip V Holmes ${ }^{5}$ and David Weinshenker*,I \\ 'Department of Human Genetics, Emory University School of Medicine, Atlanta, GA, USA; '2Department of Pharmacology, Emory University \\ School of Medicine, Atlanta, GA, USA; ${ }^{3}$ Department of Physiology and Pharmacology, University of Georgia, Athens, GA, USA; ${ }^{4}$ Department of \\ Ophthalmology, Emory University School of Medicine, Atlanta, GA, USA; ${ }^{5}$ Department of Psychology, University of Georgia, Athens, GA, USA
}

\begin{abstract}
The antialcoholism medication disulfiram (Antabuse) inhibits aldehyde dehydrogenase (ALDH), which results in the accumulation of acetaldehyde upon ethanol ingestion and produces the aversive 'Antabuse reaction' that deters alcohol consumption. Disulfiram has also been shown to deter cocaine use, even in the absence of an interaction with alcohol, indicating the existence of an ALDH-independent therapeutic mechanism. We hypothesized that disulfiram's inhibition of dopamine $\beta$-hydroxylase (DBH), the catecholamine biosynthetic enzyme that converts dopamine (DA) to norepinephrine (NE) in noradrenergic neurons, underlies the drug's ability to treat cocaine dependence. We tested the effects of disulfiram on cocaine and food self-administration behavior and drug-primed reinstatement of cocaine seeking in rats. We then compared the effects of disulfiram with those of the selective DBH inhibitor, nepicastat. Disulfiram, at a dose $(100 \mathrm{mg} / \mathrm{kg}$, i.p.) that reduced brain NE by $\sim 40 \%$, did not alter the response for food or cocaine on a fixed ratio I schedule, whereas it completely blocked cocaine-primed $(10 \mathrm{mg} / \mathrm{kg}$, i.p.) reinstatement of drug seeking following extinction. A lower dose of disulfiram $(10 \mathrm{mg} / \mathrm{kg})$ that did not reduce NE had no effect on cocaine-primed reinstatement. Nepicastat recapitulated the behavioral effects of disulfiram $(100 \mathrm{mg} / \mathrm{kg})$ at a dose $(50 \mathrm{mg} / \mathrm{kg}$, i.p.) that produced a similar reduction in brain NE. Food-primed reinstatement of food seeking was not impaired by DBH inhibition. Our results suggest that disulfiram's efficacy in the treatment of cocaine addiction is associated with the inhibition of $\mathrm{DBH}$ and interference with the ability of environmental stimuli to trigger relapse.

Neuropsychopharmacology (2010) 35, 2440-2449; doi:I0.1038/npp.20 I0. I27; published online 25 August 2010
\end{abstract}

Keywords: dopamine $\beta$-hydroxylase; disulfiram; nepicastat; norepinephrine; cocaine; reinstatement

\section{INTRODUCTION}

Disulfiram (Antabuse) has been used for more than 50 years in the treatment of alcoholism (Fuller et al, 1986). Disulfiram inhibits aldehyde dehydrogenase (ALDH), which results in the accumulation of acetaldehyde on ethanol ingestion. This toxic metabolite produces aversive symptoms, such as flushing, nausea, and vomiting, and a desire to avoid this reaction encourages abstinence. Because $50-90 \%$ of patients who abuse cocaine also abuse alcohol (Weiss et al, 1988; Grant and Harford, 1990; Closser and Kosten, 1992; Khalsa et al, 1992), the belief was that discouraging alcohol consumption in cocaine- and alcoholdependent individuals might lower cocaine use. Indeed,

\footnotetext{
* Correspondence: Dr D Weinshenker, Department of Human Genetics, Emory University School of Medicine, Whitehead 301, 6I5 Michael Street, Atlanta, GA 30322, USA, Tel: + I 404727 3106, Fax: + I 404727 3949, E-mail: dweinshenker@genetics.emory.edu

${ }^{6}$ These authors contributed equally to the work.

Received 2 July 2010; accepted 20 July 2010
}

disulfiram was found to reduce alcohol and cocaine intake in this patient population (Carroll et al, 1993, 1998, 2000). Surprisingly, further studies revealed that disulfiram is at least as effective at treating cocaine addicts who do not consume alcohol, and may even be more effective (George et al, 2000; Petrakis et al, 2000; Carroll et al, 2004). Therefore, an ALDH-independent mechanism must be responsible for the ability of disulfiram to promote cocaine abstinence (Weinshenker and Schroeder, 2007; Gaval-Cruz and Weinshenker, 2009).

Cocaine increases extracellular levels of dopamine (DA), norepinephrine (NE), and serotonin in the brain by blocking plasma membrane monoamine transporters. Thus, pathways critical for the production or transmission of these neurotransmitters are a reasonable place to look for targets underlying the efficacy of disulfiram in the treatment of cocaine dependence. Because the primary metabolite of disulfiram, diethyldithiocarbamate, is a copper chelator (Hald and Jacobsen, 1948; Johnston, 1953), disulfiram impairs the function of many copper-containing enzymes, including ALDH, carboxylesterase, cholinesterase, and 
dopamine $\beta$-hydroxylase (DBH). It is of particular interest that the inhibition of DBH by disulfiram reduces production of NE, with a concomitant increase in tissue levels of DA in rodents (Goldstein, 1966; Musacchio et al, 1966; Bourdélat-Parks et al, 2005). Disulfiram also decreases NE and its metabolites in the urine, blood, and CSF of humans (Takahashi and Gjessing, 1972; Major et al, 1979; Rogers et al, 1979; Hoeldtke and Stetson, 1980; Rosen and Lobo, 1987; Paradisi et al, 1991). We have shown that disulfiram has no effect on catecholamine levels in DBH knockout (Dbh-/-) mice, which lack NE, indicating that disulfiram's effects on NE and DA are mediated solely by DBH inhibition (Bourdélat-Parks et al, 2005). Disulfiram also inhibits cocaine-metabolizing enzymes and increases peak plasma cocaine levels under some conditions in humans (McCanceKatz et al, 1998a, b; Baker et al, 2007), but not in rodents (Gaval-Cruz and Weinshenker, 2008, 2009).

The efficacy of disulfiram in treating cocaine dependence has been attributed to several different mechanisms, including a decrease in cocaine reward, an increase in cocaine aversion, and as a 'DA replacement therapy' that elevates DA levels and restores normal reward function in hypodopaminergic addicts (Weinshenker and Schroeder, 2007; Sofuoglu et al, 2008; Gaval-Cruz and Weinshenker, 2009); however, the data have been ambiguous. Different human laboratory studies report that genetic or pharmacological DBH inhibition increases cocaine-induced paranoia and decreases, increases, or has no effect on psychostimulant-induced euphoria (Hameedi et al, 1995; McCance-Katz et al, 1998a, b; Cubells et al, 2000; Petrakis et al, 2000; Baker et al, 2007; Kalayasiri et al, 2007; Sofuoglu et al, 2008). In rodents, disulfiram decreases the locomotor-activating effects of acute cocaine administration, but facilitates cocaine sensitization (Maj et al, 1968; Haile et al, 2003).

The available human and animal data provide us a hazy picture of how disulfiram discourages cocaine use. The influence of disulfiram on the reinforcing properties of cocaine is yet to be investigated in an animal model, and whereas DBH inhibition has been suggested to underlie disulfiram's efficacy, this hypothesis has not been tested directly. In an effort to resolve these issues, we assessed the effects of disulfiram in operant rat paradigms of drug taking (cocaine self-administration) and relapse (cocaine-primed reinstatement) at doses that inhibit DBH in the brain. To determine whether the effects of disulfiram were mediated by inhibition of $\mathrm{DBH}$, we used the selective $\mathrm{DBH}$ inhibitor, nepicastat. Nepicastat is a direct, competitive inhibitor of $\mathrm{DBH}$ with greater potency than disulfiram $\left(\mathrm{IC}_{50}=9 \mathrm{nM}\right.$ for nepicastat $v s \quad \mathrm{IC}_{50} \cong 1 \mu \mathrm{M}$ for disulfiram; Green, 1964; Goldstein, 1966; Stanley et al, 1997), as well as better selectivity (does not chelate copper, no significant interaction with a panel of other enzymes and receptors tested, including ALDH and tyrosine hydroxylase, the rate-limiting enzyme in catecholamine biosynthesis) (Stanley et al, 1997; $\mathrm{K}$ Walker, Roche Biosciences, personal communication).

\section{MATERIALS AND METHODS}

\section{Subjects}

Male Sprague-Dawley rats (175-200 g) were purchased from Charles River (Wilmington, MA). All subjects were main- tained in a temperature-controlled environment on a 12-h reverse light/dark cycle with the lights on from 1900 to 0700 hours with ad libitum access to food and water. Rats were acclimated to the vivarium for 1 week before catheterimplantation surgery. All self-administration sessions occurred during the dark cycle and were performed using standard methods with minor modifications (McFarland and Kalivas, 2001; Fuchs et al, 2006). All animals were treated in accordance with NIH policy, and experiments were approved by the Emory IACUC committee.

\section{Drug Doses}

In initial pilot experiments, we tested the effects of disulfiram $(10,25,50,75,100$, or $200 \mathrm{mg} / \mathrm{kg}$, i.p. $)$ and nepicastat (50 or $100 \mathrm{mg} / \mathrm{kg}$, i.p.) on brain catecholamine levels and operant responding for food. Disulfiram was obtained from Sigma-Aldrich (St Louis, MO), sonicated in sterile saline, and injected as a suspension. Nepicastat was obtained from Synosia Therapeutics (South San Francisco, CA), sonicated in sterile saline containing 1.5\% DMSO and $1.5 \%$ Cremaphor EL (Sigma), and injected as a suspension. We chose the $100 \mathrm{mg} / \mathrm{kg}$ dose of disulfiram based on four criteria. First, $100 \mathrm{mg} / \mathrm{kg}$ was the maximum dose that significantly inhibited DBH, but did not impair the ability of rats to perform operant responses. Second, the $100 \mathrm{mg} / \mathrm{kg}$ dose has been shown by others to alter other behavioral effects of cocaine in rats, such as locomotor activity and sensitization (Haile et al, 2003). Third, the $100 \mathrm{mg} / \mathrm{kg}$ dose inhibits ALDH in rats and is in the range typically used for alcohol studies (Deitrich and Erwin, 1971; Yourick and Faiman, 1991; Karamanakos et al, 2001). Fourth, the $100 \mathrm{mg} / \mathrm{kg}$ dose is therapeutically relevant. The typical therapeutic dose for the cocaine studies performed in humans is $250-500 \mathrm{mg}$ per day (Carroll et al, 1998; McCance-Katz et al, 1998a,b), which translates to $\sim 3-7 \mathrm{mg} / \mathrm{kg}$ for a $70 \mathrm{~kg}$ human, or $\sim 10$-fold lower than we used in our study. Because of their higher metabolic rate, rodents require much larger doses of psychoactive drugs to produce behavioral and neurochemical effects compared with humans, and the $3-7 \mathrm{mg} / \mathrm{kg}$ dose has been shown to inhibit DBH in humans with a magnitude similar to the $100 \mathrm{mg} / \mathrm{kg}$ dose in rats (compare Vesell et al, 1971; Major et al, 1979; Rogers et al, 1979; Paradisi et al, 1991 human studies to our current rat study). Thus, use of the $100 \mathrm{mg} / \mathrm{kg}$ dose in rats is a close functional match to therapeutic doses in humans. We chose the $10 \mathrm{mg} / \mathrm{kg}$ dose of disulfiram for an additional experiment because it was the maximum dose in our pilot studies that did not significantly reduce brain NE levels. The $50 \mathrm{mg} / \mathrm{kg}$ dose of nepicastat was chosen to match the level of DBH inhibition observed with the $100 \mathrm{mg} / \mathrm{kg}$ dose of disulfiram.

\section{Quantification of Catecholamine Levels}

Rats were injected with disulfiram (10 or $100 \mathrm{mg} / \mathrm{kg}$, i.p.), nepicastat $(50 \mathrm{mg} / \mathrm{kg}$, i.p.), or vehicle (saline for disulfiram, $1.5 \%$ DMSO + 1.5\% Cremaphor EL in saline for nepicastat; $1 \mathrm{ml} / \mathrm{kg}$, i.p.). After $2 \mathrm{~h}$, rats were killed by administrating $\mathrm{CO}_{2}$, brains were removed, and the frontal cortex was dissected on ice and was frozen. The frontal cortex was chosen because it contains comparable amounts of NE and 
DA, and thus can be used to assess the DBH inhibition accurately. NE and DA levels were determined using HPLC followed by the coulometric detection. DA and NE concentrations were normalized to wet tissue weight for each sample.

Analytical samples from saline- and disulfiram-treated rats were prepared by adding 10 volumes of ice-cold mobile phase $\left(0.1 \mathrm{mM} \mathrm{NaHSO}_{4}\right.$, monohydrate $0.1 \mathrm{mM}$ EDTA, $0.2 \mathrm{mM}$ octane sulfonic acid, $6.5 \%$ acetonitrile ( $\mathrm{pH} 3.1)$ ), and sonicated until completely homogenized. Samples were centrifuged at 13.2 r.p.m. $\times 1000$ for $30 \mathrm{~min}$ at $4{ }^{\circ} \mathrm{C}$, and the supernatant was removed from the tubes. The supernatant was centrifuged again at 13.2 r.p.m. $\times 1000$ for $30 \mathrm{~min}$ at $4{ }^{\circ} \mathrm{C}$ using a $22-\mu \mathrm{m}$ filter column. The resulting eluant was injected using an ESA 542 Autosampler (ESA Biosciences, Chelmsford, MA) onto a Synergi Max-RP $4 \mu \mathrm{m}$ $(150 \times 4.6 \mathrm{~mm})$ with Security Guard precolumn filter with Max-RP cartridges (Phenomenex, Torrance, CA) at a constant rate of $1 \mathrm{ml} / \mathrm{min}$ maintained by ESA 584 pumps. An ESA CoulArray 5600A detector with a potential set at $-150,200 \mathrm{mV}$ was used to visualize the peaks. The retention time and height of NE and DA peaks were compared with reference standard solutions (Sigma). Peak heights were quantified by CoulArray software (ESA Biosciences).

Analytical samples of vehicle and nepicastat-treated rats were prepared by adding $70 \mu \mathrm{l}$ of ice-cold $0.1 \mathrm{~N}$ perchloric acid and $0.04 \%$ sodium metabisulfite to the tissue, and then sonicating until homogenized. Samples were centrifuged at 15 r.p.m. $\times 1000$ for $10 \mathrm{~min}$ at $4^{\circ} \mathrm{C}$. This supernatant was injected at a constant flow rate of $1 \mathrm{ml} / \mathrm{min}$ onto an Ultrasphere ODS $250 \times 4.6 \mathrm{~mm}$ column, $5 \mu \mathrm{m}$ (Beckman Coulter, Fullerton, CA) with mobile phase (0.1 mM EDTA; $0.35 \mathrm{mM}$ sodium octyl sulfate; $0.6 \%$ phosphoric acid; $5 \%$ acetonitrile ( $\mathrm{pH} 2.7)$ ). A coulometric electrochemical array detector (Agilent Technologies; guard cell set at $600 \mathrm{mV}$ and analytical cell at $300 \mathrm{mV}$ ) was used to visualize the peaks. The retention time, height, and area of NE and DA peaks were compared with reference standard solutions (Sigma) and quantified by ChemStation chromatography software (Agilent Technologies).

\section{Food Training}

Rats were trained to lever-press for food in standard rat operant chambers (Med Associates, St Albans, VT) before the drug exposure to facilitate acquisition of drug selfadministration, as described (Fuchs et al, 2006). Each chamber was equipped with a houselight, two levers (active and inactive), and stimulus lights above both the levers. Fan motors provided ventilation and masked noise in each chamber. A microcomputer with Logic ' 1 ' interface and MED-PC software (MED Associates) controlled schedule contingencies and recorded data. Animals had access to a water bottle and received 45-mg food pellets following active lever presses on a fixed ratio 1 (FR1) schedule, that is, the rat received a reinforcer following each active lever press. The food training sessions lasted for $8 \mathrm{~h}$, or until the animal met criteria, defined as at least $70 \%$ selection of the active lever and at least 100 food pellets obtained. Most rats met criteria on the first day of food training, but a few required 2-3 days.

\section{Surgery}

Following food training, rats were anesthetized with isoflurane and implanted with indwelling jugular catheters using standard methods. Briefly, catheters were inserted into the jugular vein and anchored with suture material and tissue adhesive. The catheter was then threaded subcutaneously through the skin between the shoulder blades, and the catheter was anchored. Catheters were flushed daily with $0.05 \mathrm{ml}$ gentamicin $(4 \mathrm{mg} / \mathrm{ml})$ and $0.1 \mathrm{ml}$ heparin solution (30 U/ml in sterile saline). Catheter patency was verified periodically by infusing $0.08-0.12 \mathrm{ml}$ of methohexital sodium (10 mg/ml, IV; Eli Lilly, Indianapolis, IN), which produces a rapid loss of muscle tone only when administered intravenously.

\section{Cocaine Self-Administration}

Daily self-administration sessions were run for $2 \mathrm{~h}$ on a FR1 schedule. At the start of each session, both active and inactive levers were extended, and rats received a noncontingent infusion of cocaine $(0.5 \mathrm{mg} / \mathrm{kg})$. During the training, each press of the active lever resulted in a cocaine infusion $(0.5 \mathrm{mg} / \mathrm{kg}$ in a volume of $167 \mu \mathrm{l} / \mathrm{kg})$ accompanied by a discrete flashing light above the lever. Following a 20-s timeout period (during which time active lever presses did not result in drug infusion), the stimulus light was extinguished, and responses were again reinforced. Responses on the inactive lever had no programmed consequences. To prevent overdose, we terminated the session early if the number of cocaine infusions exceeded 40 .

Once rats reached a stable level of responding (number of drug infusions varied by $<20 \%$ of the mean, and preference for the active lever was at least $75 \%$ for 3 consecutive days, with a minimum of 5 total days of cocaine selfadministration), the effects of disulfiram were assessed. Rats received an injection of saline $(2 \mathrm{ml} / \mathrm{kg}$, i.p.) or disulfiram $(100 \mathrm{mg} / \mathrm{kg}$, i.p.) $2 \mathrm{~h}$ before the self-administration session. The rats were then allowed 1-2 days of self-administration sessions with no pretreatment. The following day, rats received the opposite pretreatment (saline or disulfiram) $2 \mathrm{~h}$ before the self-administration session in a counterbalanced manner.

\section{Extinction}

Following the completion of the maintenance phase of cocaine self-administration, lever pressing was extinguished in daily 2-h sessions during which presses on the previously active lever no longer resulted in delivery of cocaine or presentation of cocaine-paired cues. Behavior was considered extinguished when active lever presses over 3 consecutive days were $<25 \%$ of the average number of active lever presses during the last 3 days of maintenance.

\section{Cocaine-Primed Reinstatement}

The day after extinction criteria were met, rats were pretreated with saline $(2 \mathrm{ml} / \mathrm{kg}$, i.p.) or disulfiram (10 or $100 \mathrm{mg} / \mathrm{kg}$, i.p.). After $2 \mathrm{~h}$, they were administered a noncontingent priming injection of cocaine $(10 \mathrm{mg} / \mathrm{kg}$, i.p.) and placed in the operant chambers under extinction 
conditions (ie, presses on the 'active' lever had no programmed consequences) for $2 \mathrm{~h}$. Rats then underwent a second round of extinction, as described above. When extinction criteria were met, rats were again tested for cocaine-primed reinstatement, but received the opposite pretreatment (saline or disulfiram) in a counterbalanced manner (order was randomized). Some of the rats used for the reinstatement tests were the same ones that received disulfiram at the end of the maintenance phase of cocaine self-administration, whereas others were from a separate group that did not receive any pretreatments during maintenance. We found no differences in reinstatement, and these groups were combined. To determine whether the effects of disulfiram on reinstatement were mediated by DBH inhibition, separate groups of rats went through cocaine self-administration and extinction, then were pretreated with vehicle (1.5\% DMSO, $1.5 \%$ Cremaphor EL in saline, $1 \mathrm{ml} / \mathrm{kg}$, i.p.) or nepicastat $(50 \mathrm{mg} / \mathrm{kg}$, i.p.) before counterbalanced reinstatement sessions, as described for disulfiram.

\section{Food Self-Administration}

Separate groups of rats were used for the food selfadministration and reinstatement experiments. Rats were maintained on a restricted diet of $16 \mathrm{~g}$ of normal rat chow per day, given in the evening at least $1 \mathrm{~h}$ after selfadministration sessions had ended. Parameters of food self-administration were identical to the cocaine selfadministration experiments, except that rats received a food pellet instead of a cocaine infusion for each active lever press, and sessions lasted for $1 \mathrm{~h}$ and were terminated if the reinforcers obtained exceeded 60 .

\section{Food-Primed Reinstatement}

Food-primed reinstatement of food seeking was performed using a modified version of published protocols (Sun and Rebec, 2005; Peters and Kalivas, 2006). Once the maintenance criteria for operant food self-administration were met (maintenance criteria and extinction criteria were identical to those used for cocaine-primed reinstatement), rats were pretreated with vehicle (1.5\% DMSO, $1.5 \%$ Cremaphor EL in saline, $1 \mathrm{ml} / \mathrm{kg}$, i.p.) or nepicistat ( $50 \mathrm{mg} / \mathrm{kg}$, i.p.). After $2 \mathrm{~h}$, they were placed in the operant chambers and the reinstatement session was started. Three food pellets were delivered non-contingently in the first $10 \mathrm{~s}$ of the session and the levers were presented to the subjects. As during extinction, responses on either of the levers had no programmed consequence. Throughout the $60-\mathrm{min}$ food reinstatement session, a food pellet was delivered every $3 \mathrm{~min}$ noncontingently, and responses on the formerly active and inactive levers were recorded. Rats then underwent a second round of maintenance and extinction training for operant food self-administration, as described above, and were then tested for food-primed reinstatement following the opposite pretreatment (vehicle or nepicistat) in a counterbalanced manner (order was randomized).

\section{Data Analyses}

Catecholamine level data were analyzed by Student's $t$-test, and self-administration data were analyzed by ANOVA followed by Bonferroni post hoc tests using Prism 4.0 for Macintosh.

\section{RESULTS}

\section{Disulfiram Inhibits DBH and Decreases Brain NE Levels}

Dopamine $\beta$-hydroxylase is the enzyme in the catecholamine biosynthetic pathway that converts $\mathrm{DA}$ to $\mathrm{NE}$ in noradrenergic neurons. Thus, inhibition of $\mathrm{DBH}$ has the unique effect of simultaneously decreasing NE production and increasing DA (Figure 1). To confirm previous reports that systemic disulfiram administration inhibits $\mathrm{DBH}$ in the rat brain, we measured $\mathrm{NE}, \mathrm{DA}$, and the $\mathrm{NE} / \mathrm{DA}$ ratio in the frontal cortex following administration of saline or disulfiram (100 mg/kg, i.p.). We chose the frontal cortex because it contains NE and DA in similar concentrations, thereby allowing the detection of both decreases and increases in these neurotransmitters. As expected, disulfiram was a bona fide $\mathrm{DBH}$ inhibitor, as it decreased NE, increased DA, and decreased the NE/DA ratio (Figure 2). Inhibition of other catecholamine biosynthetic enzymes would have had different patterns, such as decreases in both $\mathrm{NE}$ and DA following tyrosine hydroxylase inhibition.

\section{Disulfiram has no Effect on Self-Administration of Food or Cocaine}

To ensure that we were using a dose of disulfiram that did not impair the ability of rats to perform an operant task, we assessed responding for food pellets following saline or disulfiram (100 mg/kg, i.p.) administration. Disulfiram had no effect on food responding; all rats obtained the maximum number of reinforcers possible during the session (61), regardless of pretreatment ( $n=4$ per group). To determine whether disulfiram altered the reinforcing or aversive effects of cocaine, we assessed maintenance levels of responding for cocaine infusions $(0.5 \mathrm{mg} / \mathrm{kg}$ per infusion $)$ following saline or disulfiram (100 $\mathrm{mg} / \mathrm{kg}$, i.p.). Disulfiram had no effect on cocaine self-administration (Figure 3). Repeated-measures ANOVA revealed no significant effects for active lever presses $\left(\mathrm{F}_{23,2}=0.77, p=0.48\right)$ or reinforcers obtained $\left(\mathrm{F}_{23,2}=0.97, p=0.4\right)$. Inactive lever presses were negligible $(0-2$ presses per animal) and did not differ between groups.

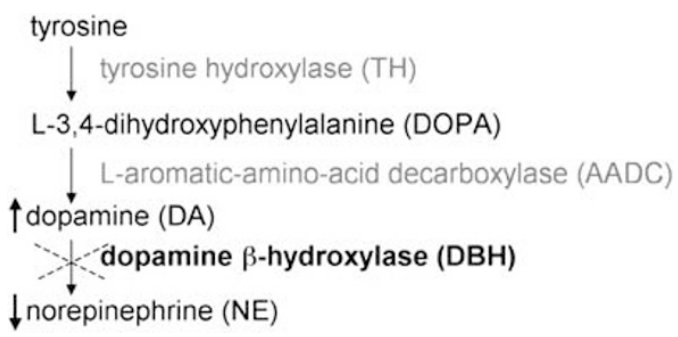

Figure I Catecholamine biosynthetic pathway. Because DBH converts $D A$ to $N E$ in noradrenergic neurons, inhibition of $D B H$ is unique in its ability to decrease NE while increasing DA. 

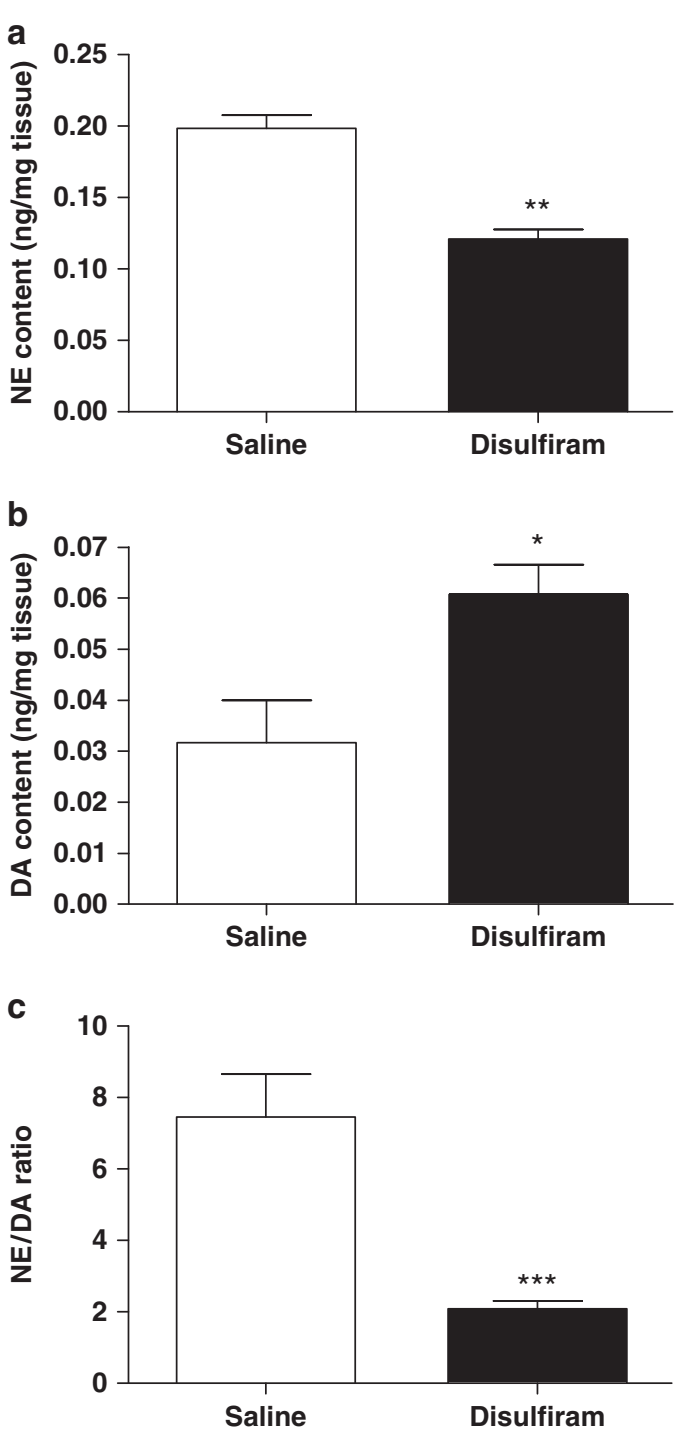

Figure 2 Effect of disulfiram on catecholamine levels in the rat frontal cortex. Shown is the mean \pm SEM for (a) NE levels, (b) DA levels, and (c) the NE/DA ratio in the frontal cortex of rats after treatment with saline or disulfiram (single injection of $100 \mathrm{mg} / \mathrm{kg}$, i.p., catecholamines measured $2 \mathrm{~h}$ after disulfiram administration by HPLC followed by electrochemical detection; $N=6$ per group). $* p<0.05$, $* * * 0.01$, **** $p<0.00$ I compared with saline.

\section{Disulfiram Blocks Cocaine-Primed Reinstatement of Cocaine Seeking}

We next tested the effects of disulfiram on drug-primed reinstatement of cocaine seeking. Following the attainment of stable self-administration and extinction, rats were treated with saline or disulfiram $(100 \mathrm{mg} / \mathrm{kg}$, i.p.) before a noncontingent priming injection of cocaine $(10 \mathrm{mg} / \mathrm{kg}$, i.p.). Rats that were pretreated with saline showed a robust reinstatement of responding on the previously active lever following cocaine prime. In contrast, disulfiram pretreatment completely blocked cocaine-primed reinstatement (Figure 4). ANOVA revealed a significant effect of treatment phase $\left(\mathrm{F}_{4,51}=8.17, p<0.0001\right)$, and Bonferroni post hoc analysis showed a significant difference between extinction

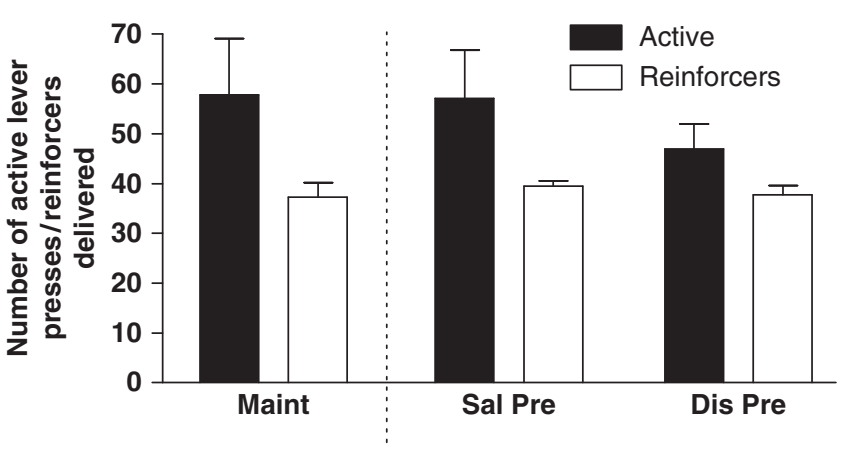

Figure 3 Disulfiram does not affect maintenance of cocaine selfadministration. After reaching maintenance levels for operant cocaine selfadministration (Maint), rats were pretreated with saline (Sal Pre) or disulfiram ( $100 \mathrm{mg} / \mathrm{kg}$, i.p.; Dis Pre) $2 \mathrm{~h}$ before cocaine self-administration sessions. Shown are mean \pm SEM active lever responses and number of reinforcers obtained over a 2-h session. Maintenance values reflect an average number of responses and reinforcers obtained over the last 3 days of maintenance. Occasional active lever pressing during the 20-s timeout periods result in more active lever presses than reinforcers received. $N=8$ per group.

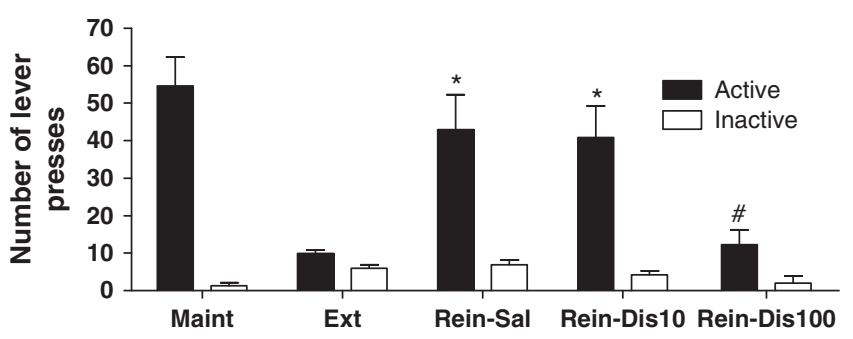

Figure 4 Disulfiram blocks cocaine-primed reinstatement. Once maintenance (Maint) and extinction (Ext) criteria for operant cocaine selfadministration were met, rats were pretreated with saline (Rein-Sal, $\mathrm{N}=13$ ) or disulfiram ( 10 or $100 \mathrm{mg} / \mathrm{kg}$, i.p.) (Rein-Dis $10, N=6$ and ReinDis $100, N=7) 2 \mathrm{~h}$ before cocaine prime (10 mg/kg, i.p.) and placement into the self-administration chambers. Shown are active and inactive lever responses. Maintenance values reflect an average of the last 3 days of maintenance sessions, and extinction values reflect an average of the last 3 days of extinction. ${ }^{*} p<0.05$ compared with active lever responses during extinction, ${ }^{\#} p<0.05$ compared with active lever responses during cocaineinduced reinstatement tests with saline pretreatment ( $N=7$ per group).

responding and cocaine-primed reinstatement following saline pretreatment $(t=3.62, p<0.05)$, but not between extinction responding and disulfiram pretreatment $(t=0.22, p>0.05)$. In addition, there was a significant difference between reinstatement responding with saline pretreatment and disulfiram pretreatment $(t=2.81$, $p<0.05)$. There was no effect of pretreatment on inactive lever responding.

We next tested the ability of a lower dose of disulfiram ( $10 \mathrm{mg} / \mathrm{kg}$, i.p.) to attenuate cocaine-primed reinstatement. This dose of disulfiram, which we found in pilot studies to be the highest one that does not significantly reduce NE levels in the frontal cortex (vehicle $=0.32 \pm 0.04 \mathrm{ng} / \mathrm{mg}$ tissue, disulfiram $=0.29 \pm 0.08, p>0.05, n=4$ per group), did not impair cocaine-primed reinstatement (Figure 4). Bonferroni post hoc analysis showed a significant difference between extinction responding and cocaine-primed reinstatement following saline $(t=3.62, p<0.05)$ or low-dose 
disulfiram pretreatment $(t=2.69, p<0.05)$, but not between saline and low-dose disulfiram pretreatment $(t=0.18$, $p>0.05)$.

\section{Nepicastat Blocks Cocaine-Primed Reinstatement of Cocaine Seeking}

The previous experiments indicated that a dose high enough to inhibit $\mathrm{DBH}$ is required for the efficacy of disulfiram in blocking cocaine-primed reinstatement. However, because DBH has many other targets, it was unclear whether $\mathrm{DBH}$ inhibition alone was sufficient to block reinstatement. Thus, we repeated the self-administration experiments with the selective $\mathrm{DBH}$ inhibitor, nepicastat, at a dose $(50 \mathrm{mg} / \mathrm{kg}$, i.p.) that inhibited $\mathrm{DBH}$ to a similar extent as the effective dose of disulfiram (100 mg/kg, i.p.) (Figure 5), and found that nepicastat pretreatment mimicked the effects of disulfiram in several ways. First, nepicastat had no affect on the maintenance phase of cocaine self-administration (Figure 6). Repeatedmeasures ANOVA revealed a nonsignificant trend for active lever presses $\left(\mathrm{F}_{26,2}=3.36, p=0.06\right)$ and no effect on reinforcers obtained $\left(\mathrm{F}_{26,2}=0.38, p=0.69\right)$. Inactive lever presses were negligible and did not differ between groups. Second, nepicastat blocked cocaine-primed reinstatement (Figure 7). Repeated-measures ANOVA revealed a significant effect of treatment phase $\left(\mathrm{F}_{3,23}=18.14, p<0.0001\right)$, and Bonferroni post hoc analysis showed a significant difference between extinction responding and cocaine-primed reinstatement following saline pretreatment $(t=5.17, p<0.01)$ and between vehicle pretreatment and nepicastat
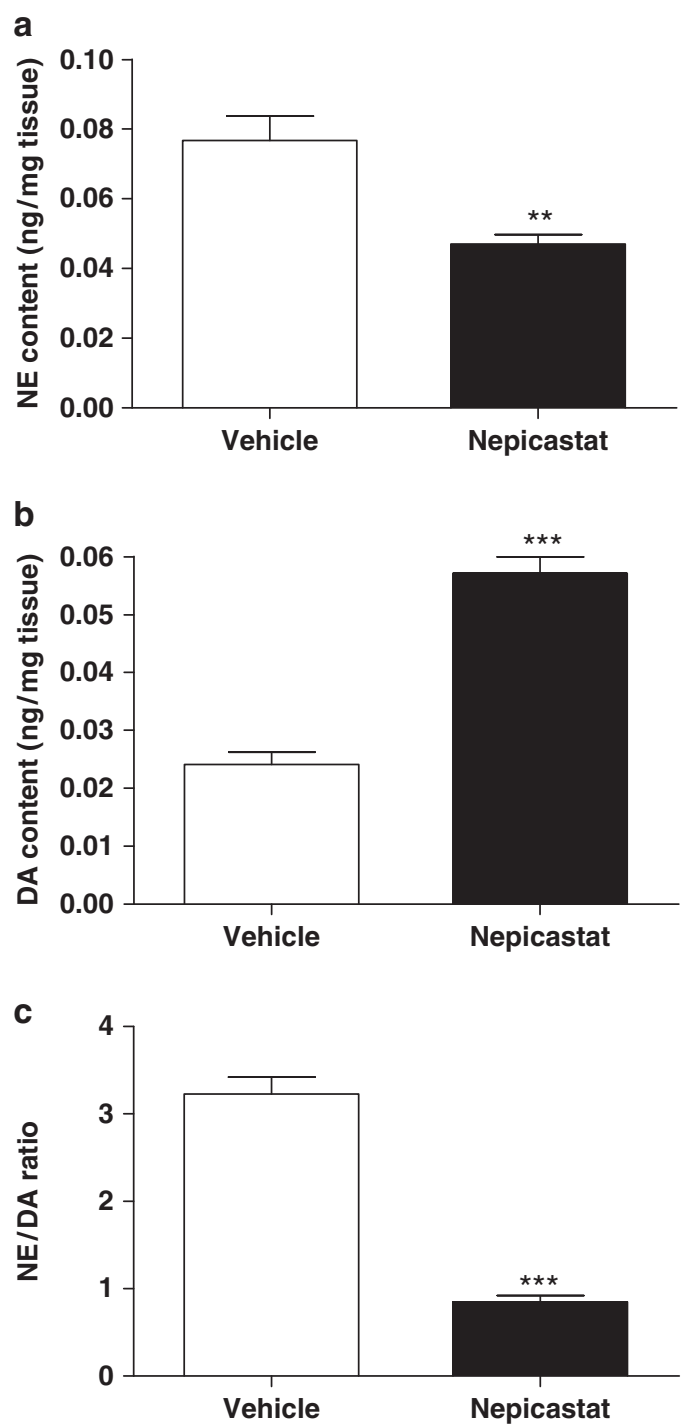

Figure 5 Effect of nepicastat on catecholamine levels in the rat frontal cortex. Shown is the mean \pm SEM for (a) NE levels, (b) DA levels, and (c) the NE/DA ratio in the frontal cortex of rats after treatment with vehicle or nepicastat (single injection of $50 \mathrm{mg} / \mathrm{kg}$, i.p., catecholamines measured $2 \mathrm{~h}$ after nepicastat administration by HPLC followed by electrochemical detection; $N=8$ per group). ${ }^{*} * 0<0.0$ l, ${ }^{*} * * p<0.00$ I compared with vehicle.

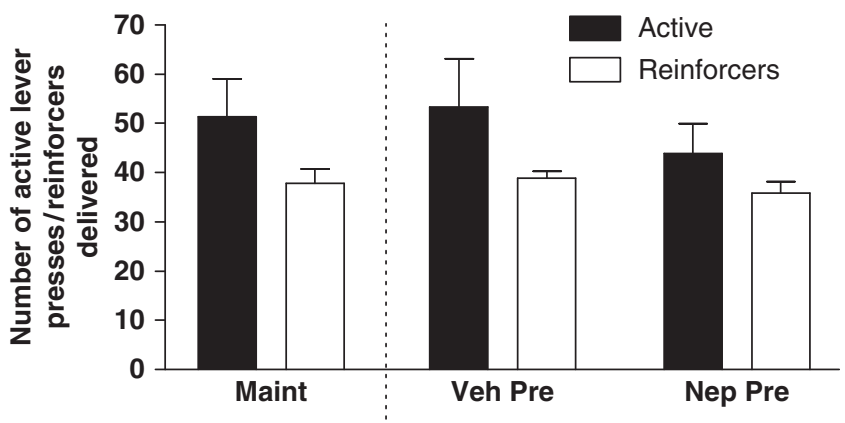

Figure 6 Nepicastat does not affect maintenance of cocaine self-administration. After reaching maintenance levels of operant cocaine self-administration (Maint), rats were pretreated with vehicle (Veh Pre) or nepicastat $(50 \mathrm{mg} / \mathrm{kg}$, i.p.; Nep Pre) $2 \mathrm{~h}$ before cocaine self-administration sessions. Shown are mean \pm SEM active lever responses and number of reinforcers obtained over a 2 -h session. Maintenance values reflect an average number of responses and reinforcers obtained over the last 3 days of maintenance. Occasional active lever pressing during the 20-s timeout periods result in more active lever presses than reinforcers received. $(N=6$ per group).

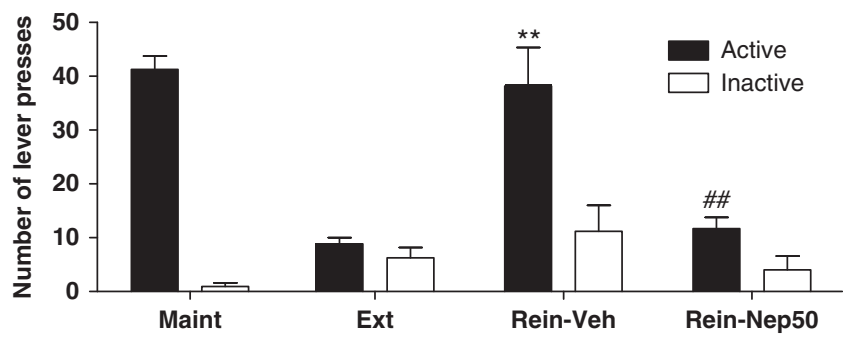

Figure 7 Nepicastat blocks cocaine-primed reinstatement. Once maintenance (Maint) and extinction (Ext) criteria for operant cocaine self-administration were met, rats were pretreated with vehicle (Rein-Veh) or nepicastat $(50 \mathrm{mg} / \mathrm{kg}$, i.p.; Rein-Nep50) $2 \mathrm{~h}$ before cocaine prime $(10 \mathrm{mg} / \mathrm{kg}$, i.p.) and placement into the self-administration chambers. Shown are mean \pm SEM active and inactive lever responses. Maintenance values reflect an average of the last 3 days of maintenance sessions, and extinction values reflect an average of the last 3 days of extinction. $* * p<0.0$ I compared with active lever responses during extinction, \#\# $p<0.0$ I compared with active lever responses during cocaine-induced reinstatement tests with vehicle pretreatment ( $N=6$ per group). 


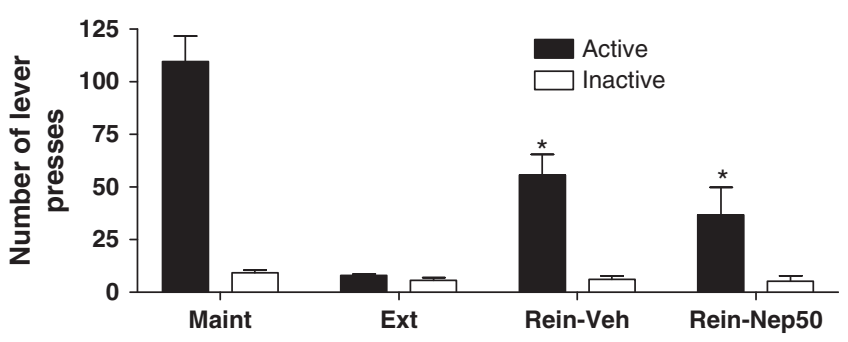

Figure 8 Nepicastat does not affect food-primed reinstatement of food seeking. Once maintenance (Maint) and extinction (Ext) criteria for operant food self-administration were met, rats were pretreated with vehicle (Rein-Veh) or nepicastat (50 mg/kg, i.p.; Rein-Nep50) $2 \mathrm{~h}$ before food prime (three pellets at beginning of the session, then one pellet every 3 min over the $60 \mathrm{~min}$ session) and placement into the self-administration chambers. Shown are mean \pm SEM active and inactive lever responses. Maintenance values reflect an average of the last 3 days of maintenance sessions, and extinction values reflect an average of the last 3 days of extinction. $* 0.05$ compared with active lever responses during extinction ( $N=7$ per group)

pretreatment ( $t=4.67, p<0.01$ ), but not between extinction responding and cocaine-primed reinstatement following nepicastat pretreatment $(t=0.5, p>0.05)$. Pretreatment had no effect on inactive lever responding. Third, nepicastat ( $50 \mathrm{mg} / \mathrm{kg}$, i.p.) had no effect on food responding; all rats obtained the maximum number of reinforcers possible during the session (61), regardless of pretreatment $(n=8$ per group).

Because the neural and molecular pathways underlying reinstatement of cocaine and food seeking are partially overlapping (Nair et al, 2009), we tested whether the attenuation of reinstatement by $\mathrm{DBH}$ inhibition was specific to cocaine, and found that nepicastat did not significantly reduce food-primed reinstatement of food seeking (Figure 8). Repeated-measures ANOVA revealed a significant effect of treatment phase $\left(\mathrm{F}_{3,27}=29.49, p<0.0001\right)$, and Bonferroni post hoc analysis showed a significant difference between extinction responding and cocaine-primed reinstatement following vehicle or nepicastat pretreatment (vehicle $t=4.27, p<0.05$; nepicastat $t=2.57, p<0.05$ ), but not between cocaine-primed reinstatement following vehicle and nepicastat pretreatment $(t=1.70, p>0.05)$. These results indicate that the blockade of cocaine-primed reinstatement by nepicastat cannot be attributed to an inability to perform the operant task and that $\mathrm{DBH}$ inhibition does not impair reinstatement of responding for a natural reward.

\section{DISCUSSION}

Disulfiram has shown promise as a treatment for cocaine dependence in several clinical trials (Carroll et al, 1993, 1998, 2000, 2004; Petrakis et al, 2000; George et al, 2000; Grassi et al, 2007; Pettinati et al, 2008). Because concurrent alcohol use is not necessary for disulfiram to have beneficial effects on cocaine addiction, an ALDH-independent mechanism is likely. Furthermore, whatever the underlying molecular mechanism, why disulfiram treatment reduces cocaine use remains unclear; several human laboratory studies have reported conflicting results over how DBH inhibition influences the rewarding and aversive effects of cocaine. The purpose of our study was therefore twofold. First, to gain insight into which aspects of addiction were being altered in the clinic, we determined which 'phase' of cocaine self-administration (ie, maintenance $v s$ reinstatement) was affected by disulfiram in rats. Second, to test the hypothesis that disulfiram was acting through $\mathrm{DBH}$ inhibition, we used a lower dose of disulfiram that does not inhibit DBH and the selective DBH inhibitor, nepicastat.

Treatments that alter the reinforcing effects of cocaine, such as dopaminergic manipulations, typically change cocaine self-administration behavior (Koob et al, 1994). Given the history of NE manipulations and cocaine selfadministration, it is not surprising that disulfiram had no effect on maintenance responding for cocaine. NE transporter (NET) inhibitors themselves do not support self-administration, and neither NET inhibitors nor adrenergic receptor antagonists alter cocaine self-administration (Yokel and Wise, 1976; Roberts et al, 1977; Woolverton, 1987; Howell and Byrd, 1991; Skjoldager et al, 1993; Tella, 1995; Wee et al, 2006; Weinshenker and Schroeder, 2007; Gaval-Cruz and Weinshenker, 2009).

Drug addiction is a chronic relapsing disorder (Hunt et al, 1971; Leshner, 1997), as patients in treatment often slip back into drug taking after periods of sobriety. Several types of stimuli can trigger drug craving and lead to relapse, including reexposure to the drug, stress, and drugassociated cues; these stimuli also trigger reinstatement in the rat model. The reliability, species generality, as well as face and construct validity of the reinstatement model are high, because they recapitulate many of the features of human addiction (Panlilio and Goldberg, 2007). In contrast to the lack of data to support an influence on the maintenance phase of psychostimulant self-administration, the role of $\mathrm{NE}$ in the reinstatement of drug seeking is clear (Erb et al, 2000; Weinshenker and Schroeder, 2007; GavalCruz and Weinshenker, 2009). Central infusion of NE itself, or the facilitation of $\mathrm{NE}$ transmission with reuptake inhibitors or inhibitory autoreceptor antagonists, induces reinstatement in rats and nonhuman primates (Lee et al, 2004; Platt et al, 2007; Brown et al, 2009). Conversely, blockade of $\beta$-adrenergic receptors prevents stress-induced reinstatement, whereas blockade of $\alpha 1$-adrenergic receptors prevents drug-primed reinstatement (Leri et al, 2002; Zhang and Kosten, 2005). Because we examined cocaine-primed reinstatement, it is likely that reinstatement was blunted following disulfiram or nepicastat pretreatment due to reduced $\mathrm{NE}$ production and a failure to engage $\alpha 1$-adrenergic receptors. The ability of $\mathrm{DBH}$ inhibition to block cocaine-primed reinstatement provides further support for the critical role of NE in this paradigm, and we propose that the clinical efficacy of disulfiram, through $\mathrm{DBH}$ inhibition and reduction of NE, reduces the risk for relapse. Most disulfiram clinical trials to date have not been designed to examine cocaine relapse specifically. It will be important to build measures into future trials that can distinguish between abstinence due to altered subjective drug effects $v s$ healthier responses to environmental triggers.

The evidence available suggests that blockade of cocaineprimed reinstatement by disulfiram involves the impairment of neurotransmission in the nucleus accumbens 
(NAc). Both DA release and glutamate release in the NAc are essential for cocaine-primed reinstatement (Schmidt et al, 2005; Kalivas, 2009). Noradrenergic neurons project to the mesocorticolimbic DA system, and NE promotes DA transmission, primarily through activation of $\alpha 1$-adrenergic receptors. For example, depletion of NE, or attenuation of $\alpha 1$-adrenergic receptor signaling through genetic, pharmacological, or neurotoxic ways, impairs psychostimulantinduced DA release in the NAc (Darracq et al, 1998; Drouin et al, 2002; Ventura et al, 2003). It is important to note that although DBH inhibition increases tissue levels of DA, it decreases DA release because NE-mediated excitation of DA neurons is reduced (Schank et al, 2006; Weinshenker and Schroeder, 2007; Weinshenker et al, 2008). Thus, the failure of a cocaine prime to provoke DA release in the NAc may underlie the efficacy of disulfiram in this paradigm. Although proof of a direct role for $\mathrm{NE}$ in regulating cocaine-induced glutamate release in the NAc is lacking, we have recently found that $\alpha 1$-adrenergic receptors are enriched in presumptive glutamatergic terminals throughout the mesocorticolimbic system (Rommelfanger et al, 2009), and we predict that a loss of noradrenergic tone may also attenuate the glutamate release essential for cocaineprimed reinstatement.

Although the blockade of cocaine-primed reinstatement by disulfiram could involve several targets, our results strongly suggest that it is mediated primarily by $\mathrm{DBH}$ inhibition, NE reduction, and a decrease in $\alpha 1 \mathrm{AR}$ signaling, as the effects of disulfiram require a dose that significantly inhibits $\mathrm{DBH}$ and are mimicked by the selective $\mathrm{DBH}$ inhibitor, nepicastat (present study), and the $\alpha 1 \mathrm{AR}$ antagonist, prazosin (Zhang and Kosten, 2005). What remains unclear is why a reduction of $\mathrm{NE} / \alpha 1 \mathrm{AR}$ signaling hampers drug-primed reinstatement, but not the maintenance phase of cocaine self-administration. Earlier findings revealed that blockade of $\alpha 1 \mathrm{ARs}$ does not affect 'conventional' operant responding for cocaine, but does attenuate the escalation of cocaine self-administration elicited by long-access 'binge' paradigms or previous drug sensitization (Zhang and Kosten, 2007; Wee et al, 2008). Altogether, these results suggest that although NE does not have a critical role in the primary reinforcing effects of cocaine, as measured by standard operant self-administration, it does have significant effects under conditions that escalate or reinstate drugseeking behavior. Furthermore, medications that impair NE production, such as disulfiram or nepicastat, may short circuit the ability of environmental triggers to promote relapse, and therefore make promising pharmacotherapies for the treatment of dependence on cocaine and other stimulants.

\section{ACKNOWLEDGEMENTS}

We thank Synosia Therapeutics for providing the nepicastat, K. Frantz and lab members for advice and technical assistance, R. Malison for helpful discussions, and C. Strauss for editing of the paper. This work was supported by the National Institute of Drug Abuse (DA017963 and DA027535 to DW, DA019746 to JRS, and DA25040 and DA015040 to MGC) and the National Eye Institute (EY004864 and P30 EY06360 to PMI).

\section{DISCLOSURE}

JPS, DAC, JRS, MAL, MG, YEO, NP, KGF, PMI, GLE, and $\mathrm{PVH}$, except for income received from their primary employers, have received no financial support or compensation from any individual or company entity over the past 3 years for research or professional service, and there are no personal financial holdings that could be perceived as constituting a conflict of interest. DW, over the past 3 years, has received research funds from Cephalon Pharmaceuticals, the developer of therapeutics for central nervous system disorders, and is co-inventor on a patent concerning the use of selective $\mathrm{DBH}$ inhibitors for the treatment of cocaine dependence (US-2010-0105748-A1; 'Methods and Compositions for Treatment of Drug Addiction').

\section{REFERENCES}

Baker JR, Jatlow P, McCance-Katz EF (2007). Disulfiram effects on responses to intravenous cocaine administration. Drug Alcohol Depend 87: 202-209.

Bourdélat-Parks BN, Anderson GM, Donaldson ZR, Weiss JM, Bonsall RW, Emery MS et al (2005). Effects of dopamine betahydroxylase genotype and disulfiram inhibition on catecholamine homeostasis in mice. Psychopharmacology (Berl) 183: 72-80.

Brown ZJ, Tribe E, D'souza NA, Erb S (2009). Interaction between noradrenaline and corticotrophin-releasing factor in the reinstatement of cocaine seeking in the rat. Psychopharmacology (Berl) 203: 121-130.

Carroll KM, Fenton LR, Ball SA, Nich C, Frankforter TL, Shi J et al (2004). Efficacy of disulfiram and cognitive behavior therapy in cocaine-dependent outpatients: a randomized placebocontrolled trial. Arch Gen Psychiatry 61: 264-272.

Carroll KM, Nich C, Ball SA, McCance E, Frankforter TL, Rounsaville BJ (2000). One-year follow-up of disulfiram and psychotherapy for cocaine-alcohol users: sustained effects of treatment. Addiction 95: 1335-1349.

Carroll KM, Nich C, Ball SA, McCance E, Rounsavile BJ (1998). Treatment of cocaine and alcohol dependence with psychotherapy and disulfiram. Addiction 93: 713-727.

Carroll KM, Rounsaville BJ, Bryant KJ (1993). Alcoholism in treatment-seeking cocaine abusers: clinical and prognostic significance. J Stud Alcohol 54: 199-208.

Closser MH, Kosten TR (1992). Alcohol and cocaine abuse. A comparison of epidemiology and clinical characteristics. Recent Dev Alcohol 10: 115-128.

Cubells JF, Kranzler HR, McCance-Katz E, Anderson GM, Malison RT, Price LH et al (2000). A haplotype at the DBH locus, associated with low plasma dopamine beta-hydroxylase activity, also associates with cocaine-induced paranoia. $\mathrm{Mol}$ Psychiatry 5: 56-63.

Darracq L, Blanc G, Glowinski J, Tassin JP (1998). Importance of the noradrenaline-dopamine coupling in the locomotor activating effects of D-amphetamine. J Neurosci 18: 2729-2739.

Deitrich RA, Erwin VG (1971). Mechanism of the inhibition of aldehyde dehydrogenase in vivo by disulfiram and diethyldithiocarbamate. Mol Pharmacol 7: 301-307.

Drouin C, Darracq L, Trovero F, Blanc G, Glowinski J, Cotecchia S et al (2002). Alphalb-adrenergic receptors control locomotor and rewarding effects of psychostimulants and opiates. J Neurosci 22: 2873-2884.

Erb S, Hitchcott PK, Rajabi H, Mueller D, Shaham Y, Stewart J (2000). Alpha-2 adrenergic receptor agonists block stressinduced reinstatement of cocaine seeking. Neuropsychopharmacology 23: 138-150. 
Fuchs RA, Branham RK, See RE (2006). Different neural substrates mediate cocaine seeking after abstinence $v s$ extinction training: a critical role for the dorsolateral caudate-putamen. J Neurosci 26: 3584-3588.

Fuller RK, Branchey L, Brightwell DR, Derman RM, Emrick CD, Iber FL et al (1986). Disulfiram treatment of alcoholism. A Veterans Administration cooperative study. JAMA 256: 1449-1455.

Gaval-Cruz M, Weinshenker D (2008). Effects of disulfiram and dopamine $\beta$-hydroxylase knockout on cocaine-induced seizures. Pharmacol Biochem Behav 89: 556-562.

Gaval-Cruz M, Weinshenker D (2009). Mechanisms of disulfiraminduced cocaine abstinence: Antabuse and cocaine relapse. Mol Interv 9: 175-187.

George TP, Chawarski MC, Pakes J, Carroll KM, Kosten TR, Schottenfeld RS (2000). Disulfiram vs placebo for cocaine dependence in buprenorphine-maintained subjects: a preliminary trial. Biol Psychiatry 47: 1080-1086.

Goldstein M (1966). Inhibition of norepinephrine biosynthesis at the dopamine-beta-hydroxylation stage. Pharmacol Rev 18: 77-82.

Grant BF, Harford TC (1990). Concurrent and simultaneous use of alcohol with cocaine: results of national survey. Drug Alcohol Depend 25: 97-104.

Grassi MC, Cioce AM, Giudici FD, Antonilli L, Nencini P (2007). Short-term efficacy of disulfiram or naltrexone in reducing positive urinalysis for both cocaine and cocaethylene in cocaine abusers: a pilot study. Pharmacol Res 55: 117-121.

Green AL (1964). The inhibition of dopamine- $\beta$-oxidase by chelating agents. Biochim Biophys Acta 81: 394-397.

Haile CN, During MJ, Jatlow PI, Kosten TR, Kosten TA (2003). Disulfiram facilitates the development and expression of locomotor sensitization to cocaine in rats. Biol Psychiatry 54: 915-921.

Hald J, Jacobsen E (1948). A drug sensitizing the organism to ethyl alcohol. Lancet 2: 1001-1004.

Hameedi FA, Rosen MI, McCance-Katz EF, McMahon TJ, Price LH, Jatlow PI et al (1995). Behavioral, physiological, and pharmacological interaction of cocaine and disulfiram in humans. Biol Psychiatry 37: 560-563.

Hoeldtke RD, Stetson PL (1980). An in vivo tritium release assay of human dopamine beta-hydroxylase. J Clin Endocrinol Metab 51: 810-815.

Howell LL, Byrd LD (1991). Characterization of the effects of cocaine and GBR 12909, a dopamine uptake inhibitor, on behavior in the squirrel monkey. J Pharmacol Exp Ther 258: 178-185.

Hunt WA, Barnett LW, Branch LG (1971). Relapse rates in addiction programs. J Clin Psychol 27: 455-456.

Johnston CD (1953). The in vitro reaction between tetraethylthiuram disulfide (Antabuse) and glutathione. Arch Biochem Biophys 44: 249-251.

Kalayasiri R, Sughondhabirom A, Gueorguieva R, Coric V, Lynch WJ, Lappalainen J et al (2007). Dopamine beta-hydroxylase gene (DbetaH) $-1021 \mathrm{C} \rightarrow \mathrm{T}$ influences self-reported paranoia during cocaine self-administration. Biol Psychiatry 61: 1310-1313.

Kalivas PW (2009). The glutamate homeostasis hypothesis of addiction. Nat Rev Neurosci 10: 561-572.

Karamanakos PN, Pappas P, Stephanou P, Marselos M (2001). Differentiation of disulfiram effects on central catecholamines and hepatic ethanol metabolism. Pharmacol Toxicol 88: 106-110.

Khalsa H, Paredes A, Anglin MD (1992). The role of alcohol in cocaine dependence. Recent Dev Alcohol 10: 7-35.

Koob GF, Caine B, Markou A, Pulvirenti L, Weiss F (1994). Role for the mesocortical dopamine system in the motivating effects of cocaine. NIDA Res Monogr 145: 1-18.

Lee B, Tiefenbacher S, Platt DM, Spealman RD (2004). Pharmacological blockade of alpha2-adrenoceptors induces reinstatement of cocaine-seeking behavior in squirrel monkeys. Neuropsychopharmacology 29: 686-693.
Leri F, Flores J, Rodaros D, Stewart J (2002). Blockade of stressinduced but not cocaine-induced reinstatement by infusion of noradrenergic antagonists into the bed nucleus of the stria terminalis or the central nucleus of the amygdala. J Neurosci 22: 5713-5718.

Leshner AI (1997). Addiction is a brain disease, and it matters. Science 278: 45-47.

Maj J, egaliñski E, Wielosz M (1968). Disulfiram and the druginduced effects on motility. J Pharm Pharmacol 20: 247-248.

Major LF, Lerner P, Ballenger JC, Brown GL, Goodwin FK, Lovenberg W (1979). Dopamine-beta-hydroxylase in the cerebrospinal fluid: relationship to disulfiram-induced psychosis. Biol Psychiatry 14: 337-344.

McCance-Katz EF, Kosten TR, Jatlow P (1998a). Disulfiram effects on acute cocaine administration. Drug Alcohol Depend 52: 27-39.

McCance-Katz EF, Kosten TR, Jatlow P (1998b). Chronic disulfiram treatment effects on intranasal cocaine administration: initial results. Biol Psychiatry 43: 540-543.

McFarland K, Kalivas PW (2001). The circuitry mediating cocaineinduced reinstatement of drug-seeking behavior. J Neurosci 21: 8655-8663.

Musacchio JM, Goldstein M, Anagnoste B, Poch G, Kopin IJ (1966). Inhibition of dopamine-beta-hydroxylase by disulfiram in vivo. J Pharmacol Exp Ther 152: 56-61.

Nair SG, Adams-Deutsch T, Epstein DH, Shaham Y (2009). The neuropharmacology of relapse to food seeking: methodology, main findings, and comparison with relapse to drug seeking. Prog Neurobiol 89: 18-45.

Panlilio LV, Goldberg SR (2007). Self-administration of drugs in animals and humans as a model and an investigative tool. Addiction 102: 1863-1870.

Paradisi R, Grossi G, Pintore A, Venturoli S, Porcu E, Capelli M et al (1991). Evidence for a pathological reduction in brain dopamine metabolism in idiopathic hyperprolactinemia. Acta Endocrinol 125: 246-252.

Peters J, Kalivas PW (2006). The group II metabotropic glutamate receptor agonist, LY379268, inhibits both cocaine- and food-seeking behavior in rats. Psychopharmacology (Berl) 186: 143-149.

Petrakis IL, Carroll KM, Nich C, Gordon LT, McCance-Katz EF, Frankforter $\mathrm{T}$ et al (2000). Disulfiram treatment for cocaine dependence in methadone-maintained opioid addicts. Addiction 95: 219-228.

Pettinati HM, Kampman KM, Lynch KG, Xie H, Dackis C, Rabinowitz AR et al (2008). A double blind, placebo-controlled trial that combines disulfiram and naltrexone for treating co-occurring cocaine and alcohol dependence. Addict Behav 33: 651-667.

Platt DM, Rowlett JK, Spealman RD (2007). Noradrenergic mechanisms in cocaine-induced reinstatement of drug seeking in squirrel monkeys. J Pharmacol Exp Ther 322: 894-902.

Roberts DC, Corcoran ME, Fibiger HC (1977). On the role of ascending catecholaminergic systems in intravenous self-administration of cocaine. Pharmacol Biochem Behav 6: 615-620.

Rogers WK, Benowitz NL, Wilson KM, Abbott JA (1979). Effect of disulfiram on adrenergic function. Clin Pharmacol Ther 25: 469-477.

Rommelfanger KS, Mitrano DA, Smith Y, Weinshenker D (2009). Light and electron microscopic localization of alpha-1 adrenergic receptor immunoreactivity in the rat striatum and ventral midbrain. Neuroscience 158: 1530-1540.

Rosen GF, Lobo RA (1987). Further evidence against dopamine deficiency as the cause of inappropriate gonadotropin secretion in patients with polycystic ovary syndrome. J Clin Endocrinol Metab 65: 891-895.

Schank JR, Ventura R, Puglisi-Allegra S, Alcaro A, Cole CD, Liles LC et al (2006). Dopamine beta-hydroxylase knockout mice 
have alterations in dopamine signaling and are hypersensitive to cocaine. Neuropsychopharmacology 31: 2221-2230.

Schmidt HD, Anderson SM, Famous KR, Kumaresan V, Pierce RC (2005). Anatomy and pharmacology of cocaine priming-induced reinstatement of drug seeking. Eur J Pharmacol 526: 65-76.

Skjoldager P, Winger G, Woods JH (1993). Effects of GBR 12909 and cocaine on cocaine-maintained behavior in rhesus monkeys. Drug Alcohol Depend 33: 31-39.

Sofuoglu M, Poling J, Waters A, Sewell A, Hill K, Kosten T (2008). Disulfiram enhances subjective effects of dextroamphetamine in humans. Pharmacol Biochem Behav 90: 394-398.

Stanley WC, Li B, Bonhaus DW, Johnson LG, Lee K, Porter S et al (1997). Catecholamine modulatory effects of nepicastat (RS-25560-197), a novel, potent and selective inhibitor of dopamine-beta-hydroxylase. Br J Pharmacol 121: 1803-1809.

Sun W, Rebec GV (2005). The role of prefrontal cortex D1-like and D2-like receptors in cocaine-seeking behavior in rats. Psychopharmacology (Berl) 177: 315-323.

Takahashi S, Gjessing LR (1972). Studies of periodic catatonia. IV. Longitudinal study of catecholamine metabolism, with and without drugs. J Psychiatr Res 9: 293-314.

Tella SR (1995). Effects of monoamine reuptake inhibitors on cocaine self-administration in rats. Pharmacol Biochem Behav 51: 687-692.

Ventura R, Cabib S, Alcaro A, Orsini C, Puglisi-Allegra S (2003). Norepinephrine in the prefrontal cortex is critical for amphetamine-induced reward and mesoaccumbens dopamine release. J Neurosci 23: 1879-1885.

Vesell ES, Passananti GT, Lee CH (1971). Impairment of drug metabolism by disulfiram in man. Clin Pharmacol Ther 12: 785-792.

Wee S, Mandyam CD, Lekic DM, Koob GF (2008). Alpha 1-noradrenergic system role in increased motivation for cocaine intake in rats with prolonged access. Eur Neuropsychopharmacol 18: $303-311$.

Wee S, Wang Z, He R, Zhou J, Kozikowski AP, Woolverton WL (2006). Role of the increased noradrenergic neurotransmission in drug self-administration. Drug Alcohol Depend 82: 151-157.

Weinshenker D, Ferrucci M, Busceti CL, Biagioni F, Lazzeri G, Liles LC et al (2008). Genetic or pharmacological blockade of noradrenaline synthesis enhances the neurochemical, behavioural, and neurotoxic effects of methamphetamine. J Neurochem 105: 471-483.

Weinshenker D, Schroeder JP (2007). There and back again: a tale of norepinephrine and drug addiction. Neuropsychopharmacology 32: 1433-1451.

Weiss RD, Mirin SM, Griffin ML, Michael JL (1988). Psychopathology in cocaine abusers. Changing trends. J Nerv Ment Dis 176: 719-725.

Woolverton WL (1987). Evaluation of the role of norepinephrine in the reinforcing effects of psychomotor stimulants in rhesus monkeys. Pharmacol Biochem Behav 26: 835-839.

Yokel RA, Wise RA (1976). Attenuation of intravenous amphetamine reinforcement by central dopamine blockade in rats. Psychopharmacology (Berl) 48: 311-318.

Yourick JJ, Faiman MD (1991). Disulfiram metabolism as a requirement for the inhibition of rat liver mitochondrial low $\mathrm{Km}$ aldehyde dehydrogenase. Biochem Pharmacol 42: 1361-1366.

Zhang XY, Kosten TA (2005). Prazosin, an alpha-1 adrenergic antagonist, reduces cocaine-induced reinstatement of drugseeking. Biol Psychiatry 57: 1202-1204.

Zhang XY, Kosten TA (2007). Previous exposure to cocaine enhances cocaine self-administration in an alpha 1-adrenergic receptor dependent manner. Neuropsychopharmacology 32: 638-645. 